First publ. in: Journal of Semantics ; 29 (2012), 3. - pp. 373-402

\title{
Negative features on negative indefinites: Evidence from split scope
}

\author{
Doris Penka \\ Universität Konstanz
}

\begin{abstract}
The assumption that negative indefinites are semantically non-negative elements associating with sentential negation has proven fruitful to account for the behaviour of negative indefinites in languages exhibiting negative concord. Under this view, negative indefinites carry a negative feature that has to be licensed by a semantic negation. This paper critically discusses and evaluates different ways in which the notion of negative features can be spelled out. Particular attention is paid to approaches that build on the indefinite nature of negative indefinites and postulate that negative indefinites have to be bound by a negation operator (e.g. Ladusaw, 1992; Kratzer, 2005). It is shown that such analyses are problematic in light of the fact that another semantic operator can take scope in between the negation and the negative indefinite. Parallel data have been discussed for negative indefinites in German and Dutch under the label split scope (e.g. Jacobs, 1980; de Swart, 2000; Abels and Martí, 2010).
\end{abstract}

\section{Introduction}

Many languages exhibit a phenomenon called negative concord (NC), where multiple morpho-syntactically negative elements contribute a single negation to the semantics. This is illustrated in the following examples from Spanish and Polish.

(1) a. Ella no ha dicho nada. (Spanish) she NEG has said n-thing 'She hasn't said anything.' 
b. Nikt mnie nie odwiedza.

(Polish)

n-person me.GEN NEG visit.3.SG.PRES

'Nobody comes to visit me.'

(from Błaszczak, 2001, 67)

Besides negative markers - such as Spanish no and Polish nie in the examples above - the items participating in $\mathrm{NC}$ are negative indefinites (NIs), also dubbed n-words after Laka (1990), like nada in Spanish and nikt in Polish. NIs in NC languages have puzzled linguists for a long time. They show an ambivalent behaviour, contributing negative force in some contexts but not in others. Compare for instance (1a) and (2). While nada in (2) is the only element that could possibly be responsible for the negative interpretation of the sentence, nada in (1a) does not seem to contribute a negation to the semantics.

(2) Nada le pudo convencer de las ventajas de nuestro plan. (Spanish) n-thing cl.3S could convince of the advantages of our plan Nothing could convince her of the advantages of our plan. (from Herburger, 2001, 293)

There are essentially three possibilities for the semantic analysis of NIs in NC languages, each coming with certain advantages and challenges. One option is to take the ambivalent behaviour of n-words at face value and assume that they are really ambiguous between semantically negative and semantically non-negative elements (Herburger (2001) provides an analysis along these lines, which is critically discussed by Zeijlstra (2004) and Penka (2010)). The challenge for such approaches lies in restricting the occurrence of the respective variant to exactly the right kind of contexts.

Another line of approaches starts from the assumption that NIs are uniformly negative quantifiers, as suggested by their being able to contribute negative force in certain contexts. This also seems to be in line with a unified cross-linguistic analysis of NIs, as NIs in languages not exhibiting NC, e.g. English, are standardly taken to denote negative quantifiers (e.g. Barwise and Cooper, 1981). To account for the phenomenon of NC, additional mechanism are invoked to reduce the number of negations in the semantic interpretation: Zanuttini (1991), Haegeman and Zanuttini (1991) and Haegeman and Zanuttini (1996) assume a processes called negation absorption, while de Swart and Sag (2002) employ quantifier resumption in a polyadic quantifier framework (see again Zeijlstra (2004) and Penka (2010) for a critical discussion of these 
approaches).

The third kind of approaches, finally, starts from the opposite assumption and argues that NIs are never semantically negative (most notably Laka, 1990; Ladusaw, 1992; Zeijlstra, 2004). In order to explain that n-words always stand in the semantic context of negation, ${ }^{1}$ such proposals posit that NIs require the presence of negation in order to be grammatical. This requirement can be implemented by assuming that NIs bear a negative feature that needs to be licensed by negation. The precise nature of this feature and the licensing relation can be spelled out in different ways, resulting in yet different analyses. One way is to subsume n-words under negative polarity items (see Laka, 1990; Giannakidou, 1998), another to assume that NC is a form of syntactic agreement (see in particular Zeijlstra, 2004)

The aim of this paper is to discuss and critically evaluate different ways to spell out the relation NIs bear towards negation under the assumption that NIs carry a negative feature. Particular attention is paid to approaches arguing that this relation is semantic in nature in the sense that the NI is semantically associated with a negation operator. Such proposals include Ladusaw (1992) and Kratzer (2005) (see also Acquaviva (1997) and Biberauer and Roberts (2010) for similar ideas). As NIs are semantically indefinites, these approaches crucially build on the analysis of indefinites as free variables in the style of Heim (1982). Under this approach, indefinites introduce free variables that can be bound by a variety of operators, giving rise in particular to the phenomenon of donkey sentences. While binding of indefinite variables is generally assumed to be unselective, the above mentioned analyses propose that NIs have to be bound by a negation operator. I show that such analyses that requires binding of the NI by a negation operator cannot be maintained as this assumption is problematic in cases where another semantic operator takes scope in between the negation and the NI. Similar cases have been discussed in the literature on NIs in non-NC languages under the label of split scope (a.o. Jacobs, 1980; Rullmann, 1995; Geurts, 1996; Potts, 2000; de Swart, 2000; Abels and Martí, 2010). I argue that such scope constellations also bear on the analysis of NIs in NC languages.

\footnotetext{
${ }^{1}$ It is not quite true that NIs always occur in the context of negation. In many languages, NIs are also possible in contexts that are not strictly negative, e.g. in Spanish and French in the complement of adversative predicates and in the standard of comparison (see a.o. Laka, 1990; Herburger, 2001). For the purpose of this paper, I am simplifying away from this issue, and refer the reader to Penka (2010) for discussion of NIs in non-strictly negative contexts.
} 
The paper is organised as follows: section 2 gives a brief overview over two possible analyses of $\mathrm{NC}$ in terms of negative features on NIs: the first approach assumes that NIs in NC languages are negative polarity items, the second takes NC to be a form of syntactic agreement. Section 3 broadens the perspective on NIs by also considering non-NC languages. In these languages NIs give rise to a phenomenon of split scope, where another operator takes scope in between the negative and the indefinite meaning component. Split scope and the equivalent of split readings in NC languages are shown to constitute important evidence on the proper analysis of NIs. Section 4 discusses several analyses of NIs proposed in the literature and shows them to be problematic, as none can account for the fact that another semantic operator can take scope in between negation and an NI. In conclusion, it is argued that the relation NIs bear towards negation is purely syntactic in nature, and no condition on the interpretation of NIs is involved.

\section{Negative indefinites as non-negative elements associating with negation}

\subsection{Negative indefinites as negative polarity items}

The first idea that comes to mind to spell out the licensing requirement between NIs and negation is probably to subsume NIs under a class of well studied items that also show a certain dependence on negation, namely negative polarity items (NPIs) (see Laka, 1990, for such a proposal). NPIs are standardly analysed as expressions that are not negative themselves but are restricted to negative contexts.

There are, however, differences between NIs and run-of-the-mill NPIs like English any, which let it appear doubtful that the former can be subsumed under the latter. In contrast to NPIs, NIs do not always co-occur with another negative expression. In some contexts, they are able to contribute negative force on their own. In Italian, for instance, NIs in preverbal position occur without the negative marker, as illustrated in example (3).

(3) Nessuno studente ha telefonato.

(Italian)

n-DET student has called

'No student called. 
Genuine NPIs in Italian, on the other hand, are not sufficient to contribute negation, even in preverbal position. This is witnessed by the fact that structures with genuine NPIs like (singular) alcuno 'any' in preverbal position are ungrammatical.

(4) *Alcuno studente ha telefonato.

(Italian)

any student has called

'*Any student called.'

Even in languages where NIs generally co-occur with a negative marker, as in Polish, there are contexts in which n-words occur without and are sufficient to induce negation. These are typically elliptical contexts, such as fragmentary answers or disjunction. NPIs, in contrast, are illicit in these contexts. For negative fragmentary answers, this is illustrated in the following contrast from Polish (taken from Błaszczak, 2001, 165):
(5) Kogo widziałeś?
Nikogo. $/{ }^{*}$ Kogokolwiek.
(Polish)
who see.2SG.PAST
n-person anybody
'Who have you seen?'
Nobody. /*Anybody.

These empirical differences in the distribution of NIs and run-of-the-mill NPIs make it doubtful that n-words can simply be subsumed under NPIs.

The assumption that NIs are semantically non-negative elements associating with negation does however not necessarily imply that they are NPIs. There is still the possibility that the licensing of NIs and NPIs is fundamentally different in nature, which accounts for the observed differences in their distribution. In recent years, a view has emerged according to which NPI licensing takes places in the semanticpragmatic component of the grammar (a.o. Kadmon and Landman, 1993; Krifka, 1995; Lahiri, 1998; Chierchia, 2006). In a nutshell, these approaches argue that the lexical semantics of NPIs involves a component rendering them infelicitous in non-negative contexts. ${ }^{2}$ Under this view, NPIs are not endowed with a feature that restricts them to negative contexts. Rather, their distribution is a consequence of their lexical semantics.

This leaves the possibility that even if NIs and NPIs are both elements that require licensing by a negation, the licensing could be of a different kind and take place in different components of the grammar. This would account for the observed

\footnotetext{
${ }^{2}$ More precisely, NPIs are felicitous only in contexts which are downward entailing (cf. Ladusaw, 1979).
} 
differences between n-words and NPIs.

\subsection{Negative concord as syntactic agreement}

According to another kind of approach, NIs come with a negative feature which requires them to enter an agreement relation with negation (a.o. Ladusaw, 1992; Brown, 1999; Zeijlstra, 2004). According to this view, NIs mark the presence of sentential negation, which itself may be realised covertly. Like other agreement phenomena, licensing of NIs is assumed to take place in the syntax.

The central idea of analysing $\mathrm{NC}$ as a form of agreement is that certain elements are morpho-syntactically marked for negation, without being semantically negative themselves. The negative form is rather a reflex of agreement with a sentential negation in the clause. In terms of lexical semantics, NIs are equivalent to positive indefinites. ${ }^{3}$ The notion of agreement is implemented in terms of feature checking, following recent assumptions within Minimalism. Zeijlstra (2004), who provides the most elaborate analysis of $\mathrm{NC}$ in terms of agreement to date, argues that elements entering an Agree relation with negation carry an uninterpretable feature [uNEG], which has to be checked against an interpretable feature [iNEG] on a c-commanding semantic negation. ${ }^{4}$ The assumption that NIs are semantically non-negative and have to be licensed by a semantic negation immediately explains why the Spanish sentence (1a), repeated as (6a) below, is interpreted as involving only one negation: only one constituent, the negative marker no, is semantically negative.

\footnotetext{
${ }^{3} \mathrm{NIs}$ are, however, not semantically equivalent to negative polarity indefinites such as anyone if proposals in the spirit of Kadmon and Landman (1993) are on the right track. According to them, the lexical semantics of NPIs involves a component (e.g. domain widening) which renders their use felicitous only in downward entailing contexts. The semantics of NIs is equivalent to the semantics of negative polarity indefinites modulo the meaning component responsible for NPI hood. In the same vein, if it turns out that the semantics of positive polarity indefinites, e.g. someone, involves a component rendering them infelicitous in downward entailing contexts, the semantic of NIs does not involve this component.

${ }^{4}$ This differs from the conception of feature pairs in Chomsky $(2000,2001)$, where uninterpretable features correspond to unvalued features serving as probe and scanning their c-command domain for a matching valued feature (a goal). In the case of negative features, an interpretable feature has to ccommand an uninterpretabel feature, if the notion of interpretability is assumed to be a semantic one. Adopting the more refined feature system proposed by Pesetsky and Torrego (2007), where interpretability is dissociated from being valued, allows both interpretable unvalued features and uninterpretable valued features.
} 
(6) a. Ella no ha dicho nada.

(Spanish)

she NEG has said n-thing

'She hasn't said anything.'

b. ella no ${ }_{[i N E G]}$ ha dicho nada ${ }_{[u N F G]}$

The NI nada is semantically non-negative, but in order to satisfy its licensing requirements, it has to check its [uNEG]-feature against an [iNEG]-feature. Since the negative marker, interpreted as sentential negation and thus bearing an [iNEG]-feature, is present and c-commands the n-word, the [uNEG]-feature on nada is checked and deleted, as indicated in $(6 \mathrm{~b})$.

Following Hiraiwa (2001), Zeijlstra assumes that Multiple Agree is possible, i.e. one [iNEG]-feature can check several [uNEG]-features simultaneously. This explains why several NIs can be licensed by the same negation, as in (7).
a. Maria non ha detto niente a nessuno.
(Italian)
Maria NEG has said n-thing to n-person
'Maria hasn't said anything to anybody.'
b. Maria non ${ }_{[\mathrm{iNEG}]}$ ha detto niente ${ }_{[\mathrm{uNFG}]}$ a nessuno $[\mathrm{uNFG}]$

In order to explain that NIs do not always co-occur with a negative marker, Zeijlstra builds on proposals by Laka (1990) and Ladusaw (1992, 1995) and argues that the licensing negation may be covert. Preverbal NIs in languages like Italian and Spanish, which are not accompanied by a negative marker, are assumed to be licensed by covert negation operator $\mathrm{Op} \neg$, bearing the feature [inEG]. For instance, the structure assumed to underlie example (8a) is as shown in (8b).
(8) a. Nadie vino.
(Spanish)
n-person came
'Nobody came.'
b. $\mathrm{Op} \neg[\mathrm{iNEG}]$ nadie $\left.{ }_{[\mathrm{uNFG}}\right]$ vino

It has to be ensured, of course, that the assumption of covert negation does not overgenerate and that a covert negation $\mathrm{Op} \neg$ can only be present in the structure if its presence is marked by an agreeing overt element. This can presumably be reduced to an economy condition, to the effect that covert operators can only be inserted into the syntactic structure if they rescue a structure that would be ungrammatical without the covert operator. The feature [uNEG] on NIs can enforce insertion of a covert 
negation, if the feature would be unlicensed otherwise. This ability of NIs to trigger the insertion of $\mathrm{Op} \neg$ can also be held responsible for the observed distributional differences between NIs and NPIs. Since uninterpretable negative features have to be deleted before Spell Out, $\mathrm{Op} \neg$ is inserted to save the derivation from crashing, if there are no overt elements bearing the feature [inEG]. Structures with unlicensed NPIs, in contrast, have been argued to be unobjectionable in the syntax, but give rise to contradictory interpretations, and thus are ruled out by the semantic-pragmatic component (cf. Krifka, 1995; Lahiri, 1998; Chierchia, 2006). As unlicensed NPIs under this view are not ungrammatical in the strict sense, they cannot enforce insertion of a covert negation operator.

Zeijlstra (2004) attributes the different patterns of co-occurrence with a negative marker, which NIs exhibit in different languages, to a difference in the semantic status of the negative marker. In languages where preverbal NIs occur without a negative marker on the verb, as in Spanish, the negative marker is assumed to be semantically negative and bear the feature [iNEG]. In languages like Polish and Russian, in contrast, where NIs always co-occur with a negative marker, the negative marker on the verb is itself analysed as a semantically empty concord item. As such it carries the feature [uNEG], like NIs. The semantic negation is assumed to be a covert negation operator. This means that in Polish and Russian, semantic negation is never realised overtly, but always marked by the presence of a negative marker or NIs. For illustration, the structure underlying the Polish sentence (1b), repeated as (9a) below, is given in (9b).
(9) a. Nikt mnie nie odwiedza.
n-person me.GEN NEG visit.3.SG.PRES
'Nobody comes to visit me.'

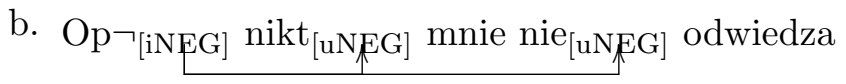

In sum, an analysis of NIs in NC languages in terms of agreement captures the phenomenon of $\mathrm{NC}$ and accounts for different patterns of $\mathrm{NC}$ by reducing them to a difference in the semantic status of the negative marker. There are, however, still open questions and different ways in which the notion of a negative feature responsible for agreement can be spelled out. These will be taken up in section 4. Before doing so I want to introduce data that have been discussed in the literature on NIs in non-NC languages and that also turn out to be crucial evidence for the analysis of NIs in NC languages. 


\section{Split readings}

\subsection{Split readings in non-NC languages}

In contrast to NC languages, in non-NC languages, each NI contributes a negation to the semantics and the problems discussed for $\mathrm{NC}$ do not arise. It thus seems simplest to assume that NIs in non-NC languages are negative quantifiers, as it is often done (e.g. Zeijlstra, 2004). There is, however, evidence indicating that in non-NC languages, too, NIs are associated with sentential negation.

It has been observed for German and Dutch that NIs in certain contexts lead to split readings, where another operator takes scope in between the negative and the indefinite meaning component of NIs (for German see Bech (1955/57); Jacobs (1980, 1982, 1991); Geurts (1996), for Dutch see Rullmann (1995); de Swart (2000)). Consider the following German example.

Bei der Prüfung muss kein Professor anwesend sein.

(German) at the exam must n-DET professor present be

a. 'It is not required that there be a professor present.' $\quad \neg>$ must $>\exists$

b. 'There is no professor who is required to be present.' $\quad \neg>\exists>$ must c??'It is required that there be no professor present.' $\quad$ ??must $>\neg>\exists$

The salient reading of sentence (10) is the one paraphrased as (10a). Assuming NIs in German to be negative quantifiers, however, only the readings (10b) and (10c) can be derived, by assigning the negative quantifier either wide or narrow scope with respect to the modal verb. Reading (10c), where the negative quantifier takes narrow scope, is only marginally available. This is presumably due to the fact that modal verbs in German show a strong preference to be interpreted in the scope of negation and other negative expressions, rather than vice versa. If the negative quantifier is assumed to take scope over the modal, reading (10b) results. Here negation outscopes the modal, but at the same time, the indefinite takes wide scope too, corresponding to a de re interpretation, i.e. (10b) denies that there is a particular professor whose presence is obligatory. ${ }^{5}$ In the salient reading (10a), however, the indefinite is interpreted $d e$

\footnotetext{
${ }^{5}$ The problem carries over to approaches dissociating de re/de dicto interpretations of indefinites from the scope the indefinite takes with respect to an intensional verb (a.o. Abusch, 1994; Percus, 2000), as suggested by the existence of narrow scope de re readings (cf. Fodor, 1970). In such approaches, predicates come with a world variable, and de re readings correspond to binding of the world variable of the restric-
} 
dicto, while negation has wide scope with respect to the modal. The wide scope de re reading (10b) and the split reading (10a) differ in truth conditions, as the former can be true in situations in which the latter is false. This is the case in a situation where the examination regulations require the presence of some professor or other at the exam, but out of the three professors of the department any will do. In this situation, sentence (10) is true under reading (10b), because there is no particular professor whose presence is required at the exam. But it is false under reading (10a), as the exam regulations require that some professor or other be present. Because in reading (10a) the modal takes scope in between the negative and the indefinite meaning component of the NI, such readings have been dubbed split scope readings.

Split readings also arise when NIs serve as objects of transitive intensional verbs, as in (11).

\section{Der Verletzte braucht keinen Arzt. \\ (German)}

The injured needs n-DET doctor

a. 'The injured doesn't need a doctor.'

$\neg>$ need $>\exists$

b. 'There is no doctor the injured needs.'

$\neg>\exists>$ need

c. ' What the injured needs is not to have a doctor.'

$*$ need $>\neg>\exists$

With transitive intensional verbs, only readings are possible where negation takes wide scope with respect to the modal, i.e. the split reading (11a) and the de re reading (11b). The reading (11c) where both negation and the indefinite are interpreted below the modal is excluded. ${ }^{6}$

Split readings do not only occur in German and Dutch, but also in other Germanic languages, as the following examples from English and Norwegian illustrate.

tor predicate by the actual world. As binding of world variables requires c-command, such approaches, however, do not allow wide scope de dicto readings, which would be required to represent split readings of NIs.

${ }^{6}$ Note that in contrast to the modal verb brauchen taking an infinitival complement, transitive brauchen is not an NPI, cf. the grammaticality of (i).

(i) Der Verletzte braucht keinen Arzt. (German)

The injured needs a doctor

The fact that negation cannot take narrow scope can thus not be ascribed to the NPI-hood of the verb. Moreover, the narrow scope reading is not available with other transitive intensional verbs, e.g. suchen 'seek', either. 
(12) The company need fire no employees.

a. It is not the case that the company is obligated to fire employees.

$$
\neg>\text { need }>\exists
$$

b. There are no employees $x$ such that the company is obligated to fire $x$.

c. *The company is obligated to fire no employees. $\neg>\exists>$ need

$$
*_{\text {need }}>\neg>\exists
$$

(13) Yet here it was, a letter, addressed so plainly there could be no mistake.

'It was not possible that there was a mistake.'

$$
\neg>\text { can }>\exists
$$

J.K. Rowling, Harry Potter and the Philosopher's Stone (p. 42)
a. Vi skylder han ingen nye sjanser.
(Norwegian)
we owe him n-DET new chances
'We don't owe him any new chances.'
(from Svenonius, 2002, 125)

In the English example (12) (from Potts, 2000), the narrow scope reading (12c) is excluded, because the modal verb need (with bare infinitive) is an NPI and cannot outscope negation. But the indefinite can nevertheless be interpreted in the scope of the modal, leading to the split reading paraphrased in (12a). In (13), the indefinite obligatorily takes narrow scope with respect to the modal could, due to the presence of expletive there (cf. Milsark, 1977; Heim, 1987). But still negation takes wide scope, and the only possible interpretation is the split reading.

The existence of split readings presents a problem for an analysis of NIs in Germanic in terms of negative quantifiers. Under this analysis, negation and the indefinite form a lexical unit, cf. the lexical entry for the negative determiner no in (15). This makes it impossible that another operator takes scope in between the negation and the indefinite. ${ }^{7}$

$$
\llbracket \text { no } \rrbracket=\lambda P_{\langle e, t\rangle} \lambda Q_{\langle e, t\rangle} \cdot \neg \exists x[P(x) \wedge Q(x)]
$$

For the purpose of this paper, split readings of NIs are interesting for two reasons. First, their existence suggests that even in languages like German and English, NIs are not negative quantifiers. Rather it seems that in these languages too, NIs are

\footnotetext{
${ }^{7}$ There are analyses of split readings maintaining the assumption that NIs are negative quantifiers. Under these approaches, negative quantifiers do not quantify over individuals, but over entities of another semantic type (kinds in Geurts (1996), properties in de Swart (2000), and choice functions in Abels and Martí (2010)), which ultimately accounts for split readings.
} 
semantically associated with an independent negation that takes sentential scope. This paths the way towards a cross-linguistically unified analysis of NIs. Under this perspective, $\mathrm{NC}$ and split scope in non-NC languages are two sides of the same coin. Both phenomena arise because NIs are not inherently negative, but rather associate with sentential negation in a different position.

If the agreement analysis of NIs in NC languages is extended to Germanic, split readings are readily accounted for. ${ }^{8}$ In fact, their existence follows from the assumption that NIs are semantically non-negative indefinites licensed by negation. As NIs mark the presence of sentential negation, it is entirely expected that another operator can take scope in between negation and the NI. Assuming that the negation licensing the NI is a covert sentential negation, the underlying structure of example (11), repeated as (16) below, corresponds to (17). ${ }^{9}$

\section{Der Verletzte braucht keinen Arzt. (German)} the injured needs n-DET doctor

a. 'The injured doesn't need a doctor.'

b. 'There is no doctor the injured needs.'

c. ${ }^{*}$ 'What the injured needs is not to have a doctor.'

$$
\begin{array}{r}
\neg>\text { need }>\exists \\
\neg \exists>\text { need } \\
*_{\text {need }>\neg \exists}
\end{array}
$$

$$
\text { [ der Verletzte }[\mathrm{Op} \neg\urcorner_{[\mathrm{iNEG}]}\left[{ }_{\mathrm{vP}} \text { keinen }_{[\mathrm{uNEG}}\right. \text { Arzt braucht ]]] }
$$

The surface structure in (17) directly expresses the split reading (16a). Negation as a category adjoining to verbal projections (cf. Jacobs, 1982) takes scope above the intensional verb brauchen 'need'. The NI keinen Arzt 'no doctor', semantically corresponding to the positive indefinite a doctor, can take scope below brauchen 'need' and receive a de dicto interpretation. Alternatively, the NI can QR to a position above the intensional verb but below negation. Such an LF expresses the de re reading (16b). Crucially, the non-attested reading (16c) cannot be derived. For this, negation would have to scope under the object intensional verb, which is not possible, as negation is not contained in the NI, but rather sentential negation.

Second, examples where another semantic operator takes scope in between the

\footnotetext{
${ }^{8}$ For reasons of space, only the gist of an analysis of NIs in non-NC languages can be given in this paper. For a detailed analysis of NIs in Germanic in terms of syntactic agreement, the reader is referred to Penka (2010).

${ }^{9}$ To abstract away from V2 movement in German, syntactic structures are given for embedded word order.
} 
negation and the indefinite meaning component of NIs are also interesting in languages exhibiting NC, as they provide crucial evidence for the proper analysis of NIs in these languages. Such sentences will play an important role in the discussion in section 4 , where several analyses of NIs proposed in the literature are evaluated. In NC languages the problem of split scope does not arise, as the negation and the indefinite are each realised in their scope position. How the equivalents of split readings are expressed in NC languages is the topic of the next subsection.

\subsection{The equivalent of split readings in NC languages}

In NC languages, the equivalent of split readings are expressed transparently in the sense that there is a negative marker on the intensional verb, in addition to an NI. This is illustrated in the Spanish sentence (18) which corresponds to the German example (10) discussed in the previous subsection.

(18) Durante el examen no tiene por que estar presente ningún professor. during the exam NEG has for COMP be present n-DET professor 'It is not required that a professor be present during the exam.' $\neg>$ must $>\exists$

The split scope effect of NIs does thus not arise in NC languages, as the two semantic components - negation and the indefinite - are each realised by a separate element. Under the assumption that the NI is semantically a non-negative indefinite and negation is expressed by the negative marker (cf. Zeijlstra, 2004), the surface structure of (18) corresponds to the reading paraphrased: negation outscopes the modal verb and the indefinite can be interpreted with narrow scope under the de dicto interpretation.

Further examples from other NC languages, for which the de dicto reading of an NI is prominent, are given in (19).
a. Poranenomu ne potriben nijakyj likar.
(Ukrainian) injured.DAT NEG need n-DET doctor 'The injured doesn't need any doctor.'
b. Ty ne dolzhen mne darit nikakich podarkov. (Russian) you NEG must me.DAT give n-DET.GEN.PL present.GEN.PL 'It is not necessary that you give me presents.'

Such examples where another operator takes scope in between negation and an NI constitute important evidence for the proper analysis of NIs in NC languages and 
will figure prominently in the discussion in the next section.

\section{The relation between NIs and negation}

A number of different ways to spell out the relation NIs enter with sentential negation have been proposed in the literature. This section shows that certain assumptions about the licensing of negative features turn out to be problematic once (the equivalent of) split readings are taken into account. The first proposal has become known as the Neg-criterion and postulates that the licensing of negative features on NIs is only possible under specifier-head agreement. Two other accounts, Ladusaw (1992) and Kratzer (2005), argue that NIs in NC languages have to be semantically bound by a negation operator. This assumption is shown to be untenable in light of the fact that another operator can take scope in between negation and the NI.

\subsection{Specifier-head agreement}

One condition that has been proposed for the licensing of NIs in the literature has become known as the Neg-criterion (Zanuttini, 1991; Haegeman and Zanuttini, 1991, 1996; Haegeman, 1995). It requires NIs to enter a configuration of specifier-head agreement with the head of a functional projection hosting negation NegP (Pollock, 1989). NIs thus have to move from their base-generated position to the specifier of NegP, as shown in (20).

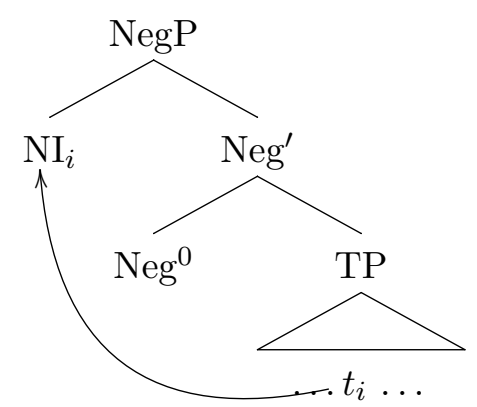

Since NIs in many languages do, in fact, occur in base position, Haegeman and Zanuttini (1991) propose that the Neg-criterion applies at the level of LF. ${ }^{10}$ Accordingly,

\footnotetext{
${ }^{10}$ To be more precise, Zanuttini (1991) and Haegeman and Zanuttini $(1991,1996)$ argue that the Negcriterion has to be met at S-structure in languages that allow scrambling (e.g. West Flemish), and at LF in other languages (e.g. Italian). Haegeman (1995), on the other hand, proposes that the Neg-criterion
} 
NIs are required to occupy the specifier of NegP at LF.

According to the proposal by Haegeman and Zanuttini, NIs are negative quantifiers, and their entering specifier-head agreement with a negative head is regarded as a necessary precondition for 'absorption' of semantic negation to take place. But ultimately, the licensing conditions of negative features are independent of the semantic status of NIs. One might combine an analysis of NIs as semantically non-negative indefinites bearing an uninterpretable negative feature with the assumption that checking of negative features is only possible under specifier-head agreement.

Assuming NIs to occupy the specifier of NegP at LF leads to a problem when the equivalent of split readings in $\mathrm{NC}$ languages are taken into account. A case in point is the following Spanish sentence.
No hace falta que te pongas ninguna chaqueta.
(Spanish)
NEG makes need COMP you wear.SUBJ n-DET jacket
a. 'You don't need to wear a jacket.'
b. 'There is no particular jacket you have to wear.'

In the salient reading of example (21), negation refers to the modal, and the NI is interpreted de dicto, as paraphrased in (21a). Observing the Neg-criterion, however, results in the following $\mathrm{LF}$ for $(21) .{ }^{11}$

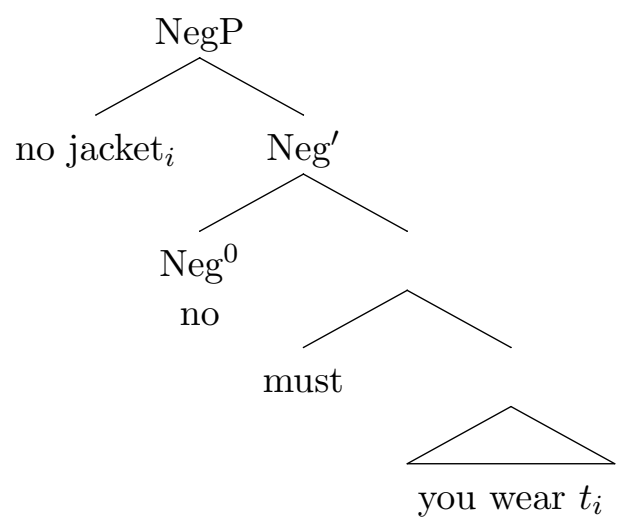

universally applies at S-structure, but can also be met by a syntactic chain headed by an abstract operator in Spec,NegP. This latter analysis leaves open the possibility that NIs reconstruct at LF. This would render the Neg-criterion a purely syntactic condition that is not motivated by semantic considerations, e.g. as a necessary precondition for 'absorption' of semantic negation.

${ }^{11}$ To enhance readability, English-style LFs are given. 
As the NI takes scope from the specifier of NegP located above the modal, it outscopes the modal. This corresponds to the de re reading of the indefinite, paraphrased in (21b). ${ }^{12}$ Therefore, NIs are invariably assigned a de re interpretation if they are assumed to occupy the specifier of $\mathrm{NegP}$ at $\mathrm{LF}$. The de dicto reading cannot be generated.

Since NIs can receive a de dicto interpretation when they are embedded under modal verbs, an LF configuration where they are in the scope of the modal must be available. Thus, NIs cannot be generally required to occupy the specifier of NegP at LF, and consequently specifier-head agreement cannot be considered a condition on the licensing of NIs. Under more recent assumptions, in particular the Minimalist Programme (Chomsky, 1995, 1998), c-command is sufficient for Agree to apply. There does not need to hold a more local relation between the elements involved in feature checking. This is what is needed in the case of negative features: in order to be licensed, an element bearing [uNEG] has to be c-commanded by an item with [iNEG].

\section{$4.2 \quad(\mathrm{Un})$ selective binding}

Ladusaw $(1992,1995)$ was one of the first to propose that NIs are semantically nonnegative and bear a negative feature that has to be licensed by a semantic negation. He also argued that the licensing negation may be covert, if the presence of covert negation is marked by an NI. His analysis, however, involves certain other assumptions, which turn out to be problematic. Crucially, Ladusaw's analysis builds on NIs being indefinite expressions. Ladusaw adopts the semantics of indefinites put forward by Heim (1982), according to which indefinite expressions denote free variables, which can be bound unselectively by a variety of operators. But in contrast to other indefinites, Ladusaw argues NIs to be selective for their binder: variables introduced by NIs have to be bound by a negation operator (or more precisely, by existential closure applying in the scope of negation).

Ladusaw's proposal is programmatic in nature, and the details are not always clear. There are different ways in which Ladusaw's proposal can be spelled out.

\footnotetext{
${ }^{12}$ In addition, as the NI takes scope above negation, the correct reading cannot be derived, if the NI is assumed to denote an existential quantifier. For this reason, analyses proposing LF-movement for NIs (Zanuttini, 1991; Haegeman and Zanuttini, 1991, 1996; Giannakidou, 1998, 2000) also argue that NIs correspond to universal quantifiers. Since $\forall \neg$ is logically equivalent to $\neg \exists$, this assumption derives a correct interpretation, albeit only a de re reading.
} 
Ladusaw $(1992,257)$ speculates that NIs raise to their binder at LF. Let us make this precise by assuming that NIs undergo QR to a position immediately below the $\exists$-closure operator triggered by negation. Let us further assume in the spirit of Heim (1982) that indefinites introduce free variables, possibly restricted by a property. As other free variables, they are interpreted via an assignment function $g$. For instance, the NIs no-one and no professor receive the following interpretations: ${ }^{13}$
a. $\llbracket$ no-one $_{i} \rrbracket^{g}=\lambda P_{\langle e, t\rangle} \cdot \operatorname{person}(g(i)) \& P(g(i))$
b. $\llbracket$ no $_{i}$ professor $\rrbracket^{g}=\lambda P_{\langle e, t\rangle}$. professor $(g(i)) \& P(g(i))$

Free variables introduced by indefinites can be bound by a variety of operators binding all free variables in their scope unselectively. For our purposes, we only need the existential closure operator defined as follows:

$$
\llbracket \exists_{1, \ldots, n} \phi \rrbracket^{g}=\exists x_{1} \ldots \exists x_{n} \llbracket \phi \rrbracket^{g\left[x_{1} / 1, \ldots, x_{n} / n\right]}
$$

The idea for analysing NIs is now that free variables corresponding to NIs have to be bound by an $\exists$-closure operator closing off the scope of negation. This means that while binding is still unselective in the sense that a binder binds all free variables in its scope, variables are selective in that they require binding by a particular operator. The question arises how it can be achieved technically that certain free variables are selective for their binder (or, for that matter, how an $\exists$-closure operator applying in the scope of negation can be told apart from an $\exists$-closure operator anywhere else). This is crucial to ensure that there is indeed a negation operator present in the structure. This question is not addressed by Ladusaw, but one way of formally implementing selectivity of variables for binders is discussed in the next subsection.

With these assumptions, a sentence like (25), where an NI enters an NC relation with a negative marker, is analysed as in (26).

Maria non ha visto nessuno.

(Italian)

Maria NEG has seen n-person

'Maria hasn't seen anybody.'

\footnotetext{
${ }^{13}$ In order to keep the discussion simple, I deviate from Heim's (1982) system in several respects. First, while Heim interprets indefinites as open sentences, i.e. as propositions, I assign them a quantifier meaning. This allows simulating Heim's rule of 'NP-prefixing' by QR. Second, instead of assuming quantifiers to range over assignment functions, I continue to assume quantification over individuals.
} 
(26) a. not $\exists_{1}\left[\text { no-one }_{1}\right]_{2}$ Maria has seen 2

b. $\neg \exists x[\operatorname{person}(x) \& \operatorname{see}(M, x)]$

For simple sentences, an analysis in the style of Ladusaw successfully accounts for $\mathrm{NC}$, as NIs denote free variables and do not involve negation. However, turning to more complex cases, namely ones involving intensional verbs, we see that it runs into difficulties. Consider the Spanish sentence (27), the counterpart of the German example (10) discussed in section 3, and the truth-conditions derived.

Durante el examen no tiene por que estar presente ningún professor. during the exam NEG has for COMP be present n-DET professor 'It is not required that a professor be present during the exam.' $\neg>$ must $>\exists$

Under the assumptions laid out above, the following LF is derived for (27), expressing the truth-conditions (29).

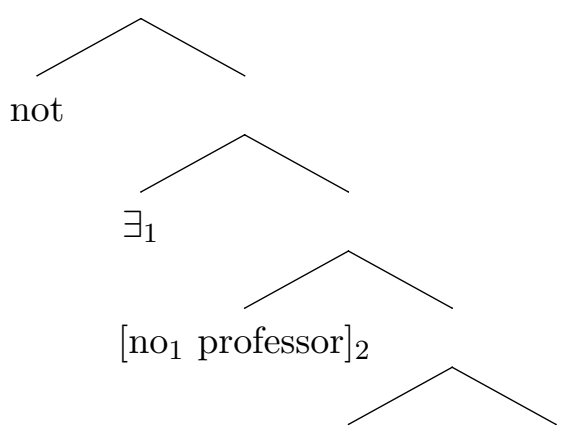

must

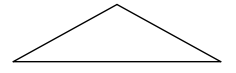

2 be present

$$
\neg \exists x\left[\operatorname{professor}(x)\left(w_{@}\right) \& \forall w[\operatorname{Acc}(w, w @) \rightarrow \operatorname{present}(x)(w)]\right]
$$

This is the de re reading, as one would expect from the fact that the NI has scope over the modal verb at LF. We thus see that only de re readings are derived if it is assumed that (i) free variables corresponding to NIs have to be bound by negation and (ii) indefinites move to a position immediately below their binder.

Let us try and give up assumption (ii) in order to derive the de dicto reading of the NI. After all, employing unselective binding seems to open up the possibility of interpreting indefinites in situ. So let us assume that binding applies at a 
distance, and indefinites are interpreted in situ. For sentence (27), his leads to the LF-representation (30).

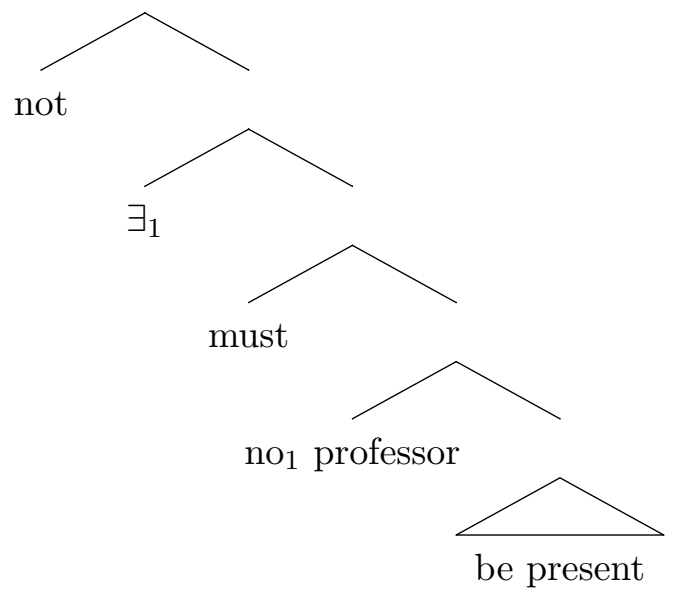

Here, the indefinite is interpreted in the scope of the modal. But the truth-conditions expressed by this LF do not correspond to the de dicto reading of the NI. In the truth-conditions derived, given in (31), the existential quantifier takes scopes over the modal, while its restrictor is below.

$$
\neg \exists x[\forall w[\operatorname{Acc}(w, w @) \rightarrow[\operatorname{professor}(x)(w) \& \operatorname{present}(x)(w)]]]
$$

This results in very weak truth-conditions, corresponding to "there is nothing in the actual world that is required to be a professor and to be present at the exam'. Assuming the accessible worlds to be worlds in which everything prescribed by the examination regulations holds, (31) is true if there is no particular individual in the actual world whose being a professor is fixed by the examination regulations. As the purpose of the examination regulations is to fix the modality of the exam, and not to determine who is a professor, this is vacuously true. ${ }^{14}$

\footnotetext{
${ }^{14}$ Reinhart (1998) discusses a related problem, the so called Donald Duck Problem, arising when whindefinites are interpreted in situ and bound by a question operator. It surfaces when the free variables introduced by wh-indefinites are bound across negation or other downward entailing operators. Reinhart's Donald Duck Problem for wh-pronouns and the problem discussed here for a particular implementation of Ladusaw's analysis of NIs show the same: if certain indefinites are required to be bound by a particular kind of operator, they have to be able to skip intervening potential binders. LFs involving unselective binding across an intervening operator while the restrictor is interpreted in situ, have very weak truth conditions. This is why in the original proposal by Heim (1982), intervening potential binders cannot be
} 
Assuming that variables introduced by NIs have to be bound by a negation operator, it is not possible to derive adequate truth-conditions for sentences like (27), where a modal intervenes between negation and an NI. In the truth-conditions (32), representing the salient reading of (27) correctly, both the existential quantifier and its restrictor are in the scope of the modal.

$$
\neg \forall w[\operatorname{Acc}(w, w @) \rightarrow \exists x[\operatorname{professor}(x)(w) \& \operatorname{present}(x)(w)]]
$$

In the corresponding LF, the variable introduced by the NI is bound by the existential closure operator applying in the scope of the modal, not the one closing off the scope of negation, as shown in (33).

$$
\text { not } \exists\left[\text { must }\left[\exists_{1} \text { no1 professor be present }\right]\right]
$$

This demonstrates that variables introduced by NIs can be bound by operators other than negation. Consequently, licensing conditions according to which free variables introduced by NIs have to be bound by ( $\exists$-closure under) a negation operator cannot be maintained.

\subsection{Hamblin alternatives}

Kratzer (2005) rephrases Ladusaw's analysis in the framework of a Hamblin semantics for indefinites, which is proposed to replace unselective binding. In a Hamblin semantics, indefinites introduce alternatives that keep expanding until they are evaluated by an operator such as the question operator or existential and universal closure. The operator evaluating the alternatives introduced by a certain indefinite expression can now be regarded as associating with the indefinite.

In a Hamblin semantics, all expressions denote sets. The denotation of a verb is a singleton set containing the respective property. The verb talk, for instance, has the lexical entry shown in (34).

$$
\llbracket \text { talk } \rrbracket^{w}=\left\{\lambda x \cdot \lambda w^{\prime} \cdot \operatorname{talk}(x)\left(w^{\prime}\right)\right\}
$$

Indefinites denote sets of individuals, conceived of as individual alternatives, i.e. they are of semantic type $e$ (rather than $\langle e, t\rangle$ ). For instance, a professor denotes the set of individuals who have the property of being a professor in the actual world.

skipped and indefinites undergo 'NP-prefixing' before unselective binding applies. 


$$
\llbracket \text { a professor } \rrbracket^{w}=\{x: \operatorname{professor}(x)(w)\}
$$

The alternatives introduced by indefinites expand (via 'pointwise' functional application). For instance, the denotation of a professor talks is the set of propositions of the form ' $x$ talks', where $x$ is a professor, as shown in (36a). In a world in which there are three professors, Professor A, Professor B and Professor C, the denotation of (36a) corresponds to (36b).
a. $\llbracket$ a professor talks $\rrbracket^{w}=\left\{p: \exists x\left[\operatorname{professor}(x)(w) \& p=\lambda w^{\prime} \cdot \operatorname{talk}(x)\left(w^{\prime}\right)\right\}\right.$
b. $\{$ that Professor A talks, that Professor B talks, that Professor C talks $\}$

In order to arrive at propositions as the denotation of sentences, alternatives have to be evaluated by operators selecting a set of propositions. These operators are propositional existential and universal closure, propositional negation and the question operator, defined in (37).

(37) Where $\alpha$ denotes a set of propositions,

a. $\llbracket \exists \alpha \rrbracket^{w}=\left\{\lambda w^{\prime} \cdot \exists p\left[p \in \llbracket \alpha \rrbracket^{w} \& p\left(w^{\prime}\right)=1\right]\right\}$

b. $\llbracket \forall \alpha \rrbracket^{w}=\left\{\lambda w^{\prime} . \forall p\left[p \in \llbracket \alpha \rrbracket^{w} \& p\left(w^{\prime}\right)=1\right]\right\}$

c. $\llbracket \operatorname{Neg} \alpha \rrbracket^{w}=\left\{\lambda w^{\prime} . \neg \exists p\left[p \in \llbracket \alpha \rrbracket^{w} \& p\left(w^{\prime}\right)=1\right]\right\}$ (from Kratzer, 2005, 123)

Applying propositional existential closure to the set of alternatives in (36) results in the singleton set containing the proposition that is true in all worlds in which some alternative in (36) is true, cf. (38).
a. $\llbracket \exists$ a professor talks $\rrbracket^{w}=\left\{\lambda w^{\prime} \cdot \exists p\left[p \in \llbracket\right.\right.$ a professor talks $\left.\left.\rrbracket^{w} \& p\left(w^{\prime}\right)\right]\right\}$
b. $\left\{\lambda w^{\prime}\right.$. talk(Professor A) $\left(w^{\prime}\right) \vee \operatorname{talk}\left(\right.$ Professor B) $\left(w^{\prime}\right) \vee \operatorname{talk}\left(\right.$ Professor C) $\left(w^{\prime}\right)$ \}

Kratzer and Shimoyama (2002) and Kratzer (2005) propose that certain indefinites are selective in the sense that the alternatives introduced by them have to be evaluated by a particular operator. Wh-indefinites, for instance, are claimed to have to associate with a question operator, while NIs in NC languages have to associate with a propositional negation, which may be realised covertly.

To this end, Kratzer and Shimoyama (2002) employ pairs of uninterpretable/ interpretable features. To ensure that these features are not purely syntactic, but go together with certain conditions on interpretation, feature movement in the style 
of Pesetsky (2000) is adopted, together with the assumption that feature movement is blocked by non-matching operators. This guarantees that indefinites semantically associate with a matching operator, because in a Hamblin semantics, the alternatives introduced by an indefinite are invariably evaluated by the operator encountered next. The alternatives introduced by an indefinite with the feature $[\mathrm{uF}]$ thus have to be evaluated by an operator bearing $[\mathrm{iF}]$. In a configuration where an element with the feature $[\mathrm{uF}]$ encounters the wrong kind of operator, a feature clash results, inducing ungrammaticality.

For NIs in NC languages, an analysis in this style looks as follows: NIs carry the feature [uNeg], which has to be checked by [iNeg] on a propositional negation. Feature checking involves movement of the respective features. This assumption improves compared to analyses requiring the whole element bearing the feature to move to the checker, as in the Neg-criterion. But assuming that a feature clash results if the wrong kind of operator is encountered still leads to problems. Here, too, examples where another operator takes scope in between negation and the indefinite are problematic. Consider our Spanish example, repeated as (39), and the structure (40) assigned to it if the indefinite is assumed to take surface scope.

Durante el examen no tiene por que estar presente ningún professor. during the exam NEG has for COMP be present n-DET professor 'It is not required that a professor be present during the exam.' $\neg>$ must $>\exists$ $(40) *^{*} \operatorname{not}_{[i N e g]}$ must $\exists_{[i \exists]}$ be present no ${ }_{[\mathrm{uNeg}]}$ professor

In (40), the next higher operator for the NI is the $\exists$-operator in the scope of the modal. ${ }^{15}$ Thus, the feature $[\mathrm{uNeg}]$ on the $\mathrm{n}$-word bumps into [i $\left.\exists\right]$ before the matching negation operator is encountered, and a feature clash inducing ungrammaticality is predicted. Consequently, (39) is falsely ruled out.

Even if the assumption that a feature clash leads to ungrammaticality was given up, ${ }^{16}$ NIs could not be forced to associate with a negation operator. As an intrinsic

\footnotetext{
${ }^{15}$ I assume, following Kratzer and Shimoyama (2002), that propositional existential closure applies in the scope of modals. Alternatively, one might build in existential closure of the scope into the lexical entry of modals, as it is done in the case of negation, cf. (37c). The effect is the same: an operator different from negation intervenes.

${ }^{16}$ One phenomenon Kratzer and Shimoyama (2002) attribute to a feature miss-match are intervention effects exhibited by wh-phrases in German, so called Beck-effects (Beck, 1996). The ungrammaticality of (i-a), for instance, is explained by assuming that movement of the feature $[\mathrm{uQ}]$ on the wh-indefinite in situ
} 
property of a Hamblin semantics, alternatives are evaluated by the next operator encountered. If the NI is interpreted in the scope of the modal, as in (41a), the alternatives introduced by it are invariably evaluated by the $\exists$-operator in the scope of the modal. Assuming again that there are the three professors, (41a) expresses (41b).

(41) a. Neg must $\exists$ no professor be present

b. $\left\{\lambda w^{\prime} . \neg \forall w^{\prime \prime}\left[\operatorname{Acc}\left(w^{\prime \prime}, w^{\prime}\right) \rightarrow\right.\right.$ [Professor A is present in $w^{\prime} \vee$ Professor B is present in $w^{\prime} \vee$ Professor $\mathrm{C}$ is present in $\left.w^{\prime}\right]$ \}

These truth conditions correspond to the split reading. But here the alternatives introduced by the NI are not evaluated by the negation, but rather by the $\exists$-operator applying in the scope of the modal. This would violate the assumption that the alternatives introduced by an NI are obligatorily evaluated by negation. If this claim is to be maintained, the NI has to be moved across the modal at LF, cf. (42). This corresponds to a de re reading.

a. Neg no professor must $\exists$ be present

b. $\left\{\lambda w^{\prime} . \neg\left[\right.\right.$ Professor A has to be present in $w^{\prime} \vee$ Professor B has to be present in $w^{\prime} \vee$ Professor $\mathrm{C}$ has to be present in $\left.\left.w^{\prime}\right]\right\}$

We see that under a Hamblin semantics, too, NIs cannot be assumed to associate with negation in a semantic sense. As far as an analysis of NIs in terms of a semantic condition is concerned, a Hamblin semantics runs into the same problems as an (un)selective binding approach. Examples where another operator takes scope in between negation and the indefinite show that negation is not always the operator which an NI encounters next and is responsible for its quantificational force. Consequently, no semantic condition can be involved in the licensing of negative features.

is blocked by the intervening [iNeg] feature on the negative marker, as shown in (i-b).

(i) a. *Was hat sie nicht wem gezeigt? (German)

what has she NEG who.DAT shown

'What didn't she show to whom?'

b. $*\left[?_{[\mathrm{iQ}]} \operatorname{was}_{[\mathrm{uQ}]}\right.$ sie nicht ${ }_{[\mathrm{iNeg}]} \operatorname{wem}_{[\mathrm{uQ}]}$ gezeigt hat $]$ 


\section{Conclusions}

This paper surveyed the idea that NIs carry uninterpretable negative features and different ways in which it can be fleshed out. Under this view, NIs are not themselves semantically negative, but associate in some sense with a sentential negation. Such an analysis does not only explain the phenomenon of $\mathrm{NC}$, but also predicts the existence of split readings, which are found in non-NC languages.

Taking into account split readings and their equivalents in NC languages was shown to provide conclusions on the nature of the relation between NIs and negation. Crucially, other operators, in particular intensional verbs, can take scope in between the negation and an indefinite realised as NI. This argues against approaches assuming that NIs semantically associate with negation, either via (un)selective binding or a Hamblin semantics. A result of the discussion is that the licensing of NIs is purely syntactic in nature, and no condition on the interpretation of NIs is involved. Moreover, checking of negative features cannot be assumed to require a specifier-head configuration.

All in all, a syntactic agreement analysis of NIs fares well. The idea that NIs carry uninterpretable negative features that have to be checked against an interpretable negative feature on a semantic negation successfully accounts for the behaviour of NIs cross-linguistically.

\section{Author's address}

Doris Penka

University of Konstanz

Department of Linguistics and Zukunftskolleg

Box 216

78457 Konstanz

Germany

email: doris.penka@uni-konstanz.de

\section{Acknowledgements}

I would like to thank the audience of the Workshop on (Un)interpretability and two anonymous reviewers for valuable comments and suggestions. The fellowship of the Zukunftskolleg and financial support of the Exzellenzinitiative to the University of 
Konstanz are gratefully acknowledged.

\section{References}

Abels, Klaus and Luisa Martí (2010), 'A unified approach to split scope', Natural Language Semantics 18, 435-470.

Abusch, Dorit (1994), 'The scope of indefinites', Natural Language Semantics 2, 83135 .

Acquaviva, Paolo (1997), The Logical Form of Negation: A Study of OperatorVariable Structures in Syntax, Garland, New York/London.

Barwise, Jon and Robin Cooper (1981), 'Generalized quantifiers and natural language', Linguistics and Philosophy 4, 159-219.

Bech, Gunnar (1955/57), Studien über das deutsche Verbum infinitum, Danske Videnskabernes Selskab: Historisk-filologiske meddelelser, Munksgaard, Kopenhagen.

Beck, Sigrid (1996), Wh-constructions and transparent Logical Form, PhD thesis, Universität Tübingen.

Biberauer, Theresa and Ian Roberts (2010), Negative words and related expressions: a new perspective on some familiar puzzles, in R.Ingham and P.L'Arrivée, eds, 'Cycles of Grammaticalization. Comparative Views on the History of Negation', Cambridge University Press.

Błaszczak, Joanna (2001), Investigation into the Interaction between the Indefinites and Negation, studia grammatica 51, Akademie Verlag, Berlin.

Brown, Sue (1999), The Syntax of Negation in Russian: a Minimalist Approach, CSLI Publications, Stanford.

Chierchia, Gennaro (2006), 'Broaden your views. Implicatures of domain widening and the 'logicality' of language', Linguistic Inquiry 37(4), 535-590.

Chomsky, Noam (1995), The minimalist program, MIT Press, Cambridge, MA.

Chomsky, Noam (1998), 'Minimalist inquiries: the framework', MIT working papers in linguistics.

Chomsky, Noam (2000), Minimalist inquiries, in R.Martin, D.Michaels and J.Uriagireka, eds, 'Step by step: Essays on minimalist syntax in honor of Howard Lasnik', MIT Press, Cambridge, MA, pp. 89-156. 
Chomsky, Noam (2001), Derivation by phase, in M.Kenstowicz, ed., 'Ken Hale: A life in language', MIT Press, Cambridge, MA.

de Swart, Henriëtte (2000), Scope ambiguities with negative quantifiers, in K.von Heusinger and U.Egli, eds, 'Reference and Anaphoric Relations', Kluwer Academic Publishers, Dordrecht, pp. 109-132.

de Swart, Henriëtte and Ivan A. Sag (2002), 'Negation and Negative Concord in Romance', Linguistics and Philosophy 25, 373-417.

Fodor, Janet Dean (1970), The Linguistic Description of Opaque Contexts, PhD thesis, MIT.

Geurts, Bart (1996), 'On 'No', Journal of Semantics 13, 67-86.

Giannakidou, Anastasia (1998), Polarity Sensitivity as (Non)veridical Dependency, Linguistik aktuell 23, John Benjamins, Amsterdam/Philadelphia.

Giannakidou, Anastasia (2000), 'Negative ... concord?', Natural Language and Linguistic Theory 18, 457-523.

Haegeman, Liliane (1995), The Syntax of Negation, Cambridge Studies in Linguistics 75, Cambridge University Press, Cambridge.

Haegeman, Liliane and Raffaella Zanuttini (1991), 'Negative Heads and the NEGCriterion', The Linguistic Review 8, 233-251.

Haegeman, Liliane and Raffaella Zanuttini (1996), Negative Concord in West Flemish, in A.Belletti and L.Rizzi, eds, 'Parameters and Funtional Heads. Essays in Comparative Syntax', Oxford University Press, Oxford, pp. 117-179.

Heim, Irene (1982), The Semantics of Definite and Indefinite Noun Phrases, PhD thesis, University of Massachusetts at Amherst. Published 1988 by Garland, New York.

Heim, Irene (1987), Where does the definiteness restriction apply? Evidence from the definiteness of variables, in E. J.Reuland and A. G. B.ter Meulen, eds, 'The Representation of (In)Definiteness', MIT Press, Cambridge, MA, pp. 21-42.

Herburger, Elena (2001), 'The Negative Concord Puzzle Revisited', Natural Language Semantics 9, 289-333.

Hiraiwa, Ken (2001), Multiple agree and the defective intervention constraint in Japanese, in O.Matsushansky et al., eds, 'Proceeding of the Harvard MIT Joint Conference', MIT Working Papers in Linguistics 40, Cambridge, MA, pp. 67-80. Jacobs, Joachim (1980), 'Lexical decomposition in Montague grammar', Theoretical 
Linguistics 7, 121-136.

Jacobs, Joachim (1982), Syntax und Semantik der Negation im Deutschen, Studien zur Theoretischen Linguistik 1, Fink, München.

Jacobs, Joachim (1991), Negation, in A.von Stechow and D.Wunderlich, eds, 'Semantik - Ein internationales Handbuch zeitgenössischer Forschung', de Gruyter, Berlin/New York, pp. 560-596.

Kadmon, Nirit and Fred Landman (1993), 'Any', Linguistics and Philosophy 16(4), 354-422.

Kratzer, Angelika (2005), Indefinites and the operators they depend on: From Japanese to Salish, in G. N.Carlson and F. J.Pelletier, eds, 'Reference and Quantification: The Partee Effect', CSLI Publications, Stanford, pp. 113-141.

Kratzer, Angelika and Junko Shimoyama (2002), Indeterminate pronouns: The view from Japanese, in Y.Otso, ed., 'Proceedings of the Third Tokyo Conference on Psycholinguistics', Hituzi Syobo, Tokyo.

Krifka, Manfred (1995), 'The semantics and pragmatics of polartity items', Linguistic Analysis 25, 209-258.

Ladusaw, William A. (1979), Polarity Sensitivity as Inherent Scope Relations, PhD thesis, University of Texas at Austin. Published 1980 by Garland, New York.

Ladusaw, William A. (1992), Expressing Negation, in C.Barker and D.Dowty, eds, 'Proceedings of SALT II', Ohio State Working Papers in Linguistics 40, Ohio State University, pp. 237-259.

Ladusaw, William A. (1995), Configurational Expression of Negation, in J.van der Does and J.van Eijck, eds, 'Quantifiers, Logic and Language', CSLI Publications, Stanford, pp. 203-223.

Lahiri, Utpal (1998), 'Focus and Negative Polarity in Hindi', Natural Language Semantics 6, 57-123.

Laka, Itziar (1990), Negation in Syntax: On the Nature of Functional Categories and Projections, PhD thesis, MIT.

Milsark, Gary L. (1977), 'Toward an explanation of certain peculiarities of the existential construction in English', Linguistic Analysis 3, 1-29.

Penka, Doris (2010), Negative Indefinites, number 32 in 'Oxford Studies in Theoretical Linguistics', Oxford University Press, Oxford/NY.

Percus, Orin (2000), 'Constraints on some other variables in syntax', Natural Lan- 
guage Semantics 8(3), 173-229.

Pesetsky, David (2000), Phrasal Movement and its Kin, MIT Press, Cambridge, MA.

Pesetsky, David and Esther Torrego (2007), The syntax of valuation and the interpretability of features, in S.Karimi, V.Samiian and W. K.Wilkins, eds, 'Phrasal and Clausal Architecture: Syntactic Derivation and Interpretation', Linguistik Aktuell/Linguistics Today, Benjamins, Amsterdam, pp. 262-294.

Pollock, Jean-Yves (1989), 'Verb movement, universal grammar and the structure of IP', Linguistic Inquiry 20(3), 365-424.

Potts, Christopher (2000), 'When even 'no's neg is splittsville', Jorge Hankamer's Webfest.

URL: http://ling.ucsc.edu/Jorge/index.html

Reinhart, Tanya (1998), 'Wh-in-situ in the framework of the minimalist program', Natural Language Semantics 6, 25-56.

Rullmann, Hotze (1995), 'Geen eenheid', Tabu 25(4), 194-197.

Svenonius, Peter (2002), 'Strains of Negation in Norwegian', Working Papers in Scandinavian Syntax 69, 121-146.

Zanuttini, Raffaella (1991), Syntactic Properties of Sentential Negation: A Comparative Study of Romance Languages, $\mathrm{PhD}$ thesis, University of Pennsylvania.

Zeijlstra, Hedde (2004), Sentential Negation and Negative Concord, PhD thesis, University of Amsterdam. 